\title{
Knowledge, attitude, practice and quality of life assessment in glaucoma- a cross sectional survey
}

\author{
Elfride F.S. ${ }^{1}$, Philip S. ${ }^{2}$, Kishore S.R. ${ }^{3}$ \\ ${ }^{1}$ Dr Elfride Farokh Sanjana, Professor, Department of Ophthalmology, Pondicherry Institute of Medical Sciences, \\ Kalapet, Pondicherry, India ${ }^{2}$ Dr. Serin Philip Medical Claim Officer, Dar al Shifa hospital, Kuwait, ${ }^{3}$ Dr. Kishore Sastha \\ Ram V., Lecturer, Department of Pharmacy, College of Health sciences, Mizan Tepi University SNNPR, Ethiopia
}

Address for Correspondence: Dr Elfride Farokh Sanjana, Professor, Department of Ophthalmology, Pondicherry Institute of Medical Sciences, Kalapet, Pondicherry. Email: elfridesanjana@gmail.com

\begin{abstract}
Aim: To determine knowledge, attitude and practice of patients with glaucoma and to analyze the quality of life of patients with glaucoma using the GQL-15 questionnaire. Materials and Methods: 62 patients with a known diagnosis of glaucoma and started on medical management were included in the study. On the first visit patients were counseling about the nature of the disease, dose, duration and frequency of medications, were informed of side effects and technique of instillation. On the second visit patients were assessed with a validated KAP questionnaire and GQL-15 quality of life questionnaire. The questions were administered in the local language by trained optometrists and health care personnel. Results: The inter item correlation between knowledge, attitude and practice was found to be $0.897,0.877$ and 0.765 there by validating the questionnaire. Forty nine $(87.5 \%)$ of patients were found to have adequate knowledge regarding disease, drug, dose, frequency and proper method of instillation of eye drops. Forty one (73.32\%) of patients were found to have a positive attitude towards usage of eye drops and the remaining 15(26.78\%) negative attitude. Safe practice was followed by $49(87.5 \%)$ of patients and unsafe with $7(12,57 \%)$ GQL-15 questionnaire applied at the time of second visit showed $40(71.42 \%)$ of patients with low GQL score. Conclusion: Our study highlights that awareness and dissemination of information on basic eye drop instillation technique improves patient knowledge awareness and practice patterns of this asymptomatic disease and can help patients adhere to management.
\end{abstract}

Key words: Attitude, Glaucoma, Knowledge, Practice, Quality of life questionnaire

\section{Introduction}

Global data on visual impairment has stated glaucoma to be a leading cause of irreversible blinded worldwide [1] with 11 million of these patients from India [2] with an estimated projection to 16 million by the year 2020 [3]. Due to its asymptomatic nature and lack of awareness amongst the people it largely remains under diagnosed $[4,5]$. To compound matters most patients are diagnosed in the advanced stages where very little can be done to salvage useful filed of vision in this vulnerable group of population [6.7]. Several studies have estimated the awareness of this slowly progressive asymptomatic condition in southern India $[8,9,10]$. The

Manuscript received: $04^{\text {th }}$ December 2016

Reviewed: $10^{\text {th }}$ December 2016

Author Corrected: $19^{\text {th }}$ December 2016

Accepted for Publication: 27 $7^{\text {th }}$ December 2016 other element in deciding the burden of glaucoma is the effective utilization of eye services. Several studies had estimated this social economic aspect of Glaucoma. $[11,12]$. Lowering of intraocular pressure is the only known means of treating glaucoma however it is only a surrogate marker for control of the disease. Quality of life indicators with the use of validated questionnaires has provided important insights that help make therapeutic choices and suggest alterations in the patients home environment to minimize problems and obstacles $[13,14]$. Such adaptations might permit more years of unassisted living for the elderly. Information from QOL studies can help educate newly diagnosed patients as to what may lie ahead as the disease progresses with a possible additional benefit of 
reinforcement for the need for adherence to the prescribed regimen despite the asymptomatic nature of the disease.

There isn't available literature that assesses both knowledge, attitude and practice of patients with glaucoma who are also subjected to QOL evaluation. This holistic approach might ensure better control of the intraocular pressure with subsequent slowing in the progression of the disease. In this study we have attempted the same.

\section{Materials and Methods}

This study was conducted on 62 patients of either sex with a known diagnosis of glaucoma. In addition to being subjected to a detailed comprehensive eye examination a specifically designed Knowledge, Attitude and Practice questionnaire was used on their second visit to evaluate patients knowledge and eye drop instillation technique [8]. The survey was conducted by trained optometrist and health care personnel who had adequate knowledge about the questionnaire.

The questionnaire was available in the local language and reading assistance to the illiterate was provided. Informed consent was obtained and ethics committee approval was obtained before embarking on the study .The questionnaire included three domains -knowledge which comprised of 12 closed ( yes or no) questions on the patients awareness about the disease, name, dose ,strength, frequency and storage conditions of the drug prescribed to them on a prior visit. Along with this parameters such as affordability and technique of eye drop administration was assessed. The second domain attitude comprised of 7 closed ended questions and the third practice consisted of 4 closed ended questions and 7 descriptive questions regarding the practices and usage of eye drops. Each question was allocated a score of 1 if yes and 2 if no. Each question per patient was counted for their response and expressed as a percentage. Similarly each domain was summated and knowledge of patients was expressed as adequate and inadequate, attitude as positive and negative and practice as safe and unsafe respectively in percentage.

Cronbachs alpha coefficient measures the overall correlation between items within a scale/questionnaire. AN internal consistency of greater than 0.7 and less than 0.9 was considered acceptable in justifying its use. A high alpha value suggests that the items measure the same single underlying condition. It is used to validate the specially prepared KAP questionnaire.

Glaucoma quality of life (GQL-15) Questionnaire is a specific tool for assessing quality of life in glaucoma patients [13,14]. Questions focus on visual ability, specific task performance and the impact of reduced visual ability on patients quality of life. It contains 15 rating scored questions used to assess the degree of disability caused by glaucoma. Six questions related to actions demanding functional peripheral vision, 6 relating to dark adaptation and glare, and two relating to central and near vision and one to outdoor mobility. Patients were instructed to circle the correct answer on a scalefrom1-5.

\section{Results}

The inter item correlation between knowledge, attitude and practice was found to be $0.897,0.877$ and 0.765 there by validating the questionnaire (Table 1).

Forty nine $(87.5 \%)$ of patients were found to have adequate knowledge regarding disease, drug, dose, frequency and proper method of instillation of eye drops. Remaining 7 (12.5\%) were found to have inadequate knowledge (Table 2).

Table-1: Cronbachs' Alpha Correlation Coefficient for KAP Questionnaire

\begin{tabular}{|l|l|l|}
\hline Domain & Number of items & Cronbach's alpha coeff \\
\hline Knowledge & 12 & 0.897 \\
\hline Attitude & 7 & 0.877 \\
\hline Practice & 4 & 0.765 \\
\hline
\end{tabular}


Table-2: Knowledge, attitude and practice scores- Knowledge

\begin{tabular}{|l|l|l|l|l|}
\hline S.No & Scores & Knowledge & Subjects & Percentage \\
\hline 1 & $>15$ & Adequate & 49 & 87.5 \\
\hline 2 & $<15$ & Inadequate & 7 & 12.5 \\
\hline
\end{tabular}

Table- 3: Knowledge, attitude and practice scores- Attitude

\begin{tabular}{|l|l|l|l|l|}
\hline S.No & Score & Attitude & Subjects & Percentage \\
\hline 1 & $<15$ & Positive & 41 & 73.32 \\
\hline 2 & $>15$ & Negative & 15 & 26.78 \\
\hline
\end{tabular}

Table 4: Knowledge, attitude and practice scores- Practice

\begin{tabular}{|l|l|l|l|l|}
\hline S.No & Score & Practice & Subjects & Percentage \\
\hline 1 & $<15$ & Safe & 49 & 87.5 \\
\hline 2 & $>15$ & unsafe & 7 & 12.57 \\
\hline
\end{tabular}

Table-5: Glaucoma Quality of life score (GQL-15)

\begin{tabular}{|l|l|l|l|l|}
\hline S.No & Score & GQL & Subjects & Percentage \\
\hline 1 & $<35$ & Low QOL & 40 & 71.42 \\
\hline 2 & $>35$ & High QOL & 16 & 28.57 \\
\hline
\end{tabular}

Forty one $(73.32 \%)$ of patients were found to have a positive attitude towards usage of eye drops and the remaining $15(26.78 \%)$ negative attitude (Table 3$)$. Safe practice was followed by $49(87.5 \%)$ of patients and unsafe with $7(12,57 \%)$ (Table 4)

GQL-15 questionnaire applied at the time of second visit showed 40(71.42\%) of patients with low GQL-15 score (Table 5)

\section{Discussion}

The need for health education to improve knowledge, awareness and self care practices amongst both rural and urban India cannot be over emphasized. This study evaluated the knowledge, attitude and practice on methods of instillation of eye drops as well as the GQL15 questionnaire only after the patients were counseled and instructed regarding the dose, dosing interval, method of instillation of drops in the form of pictorial leaflets in English and local language leaflets during their first consultation. Among 56 patients who reported for the second visit all patients had adequate knowledge about their disease, $43(76.78 \%)$ were aware of the name of the drug, dosage frequency and storage conditions. The right method of eye drop instillation was observed in $49(87.5 \%)$ and $41(73.21 \%)$ of patients were aware of nasolacrimal duct occlusion maneuver. In a study by Dandona $\mathrm{R}$ et all, awareness about the disease glaucoma in an urban population in South India was very poor$2.3 \%$ [8]. Another study amongst rural South India by Krishnaiah $\mathrm{S}$ et al a total of $61.1 \%$ of people did not even know what glaucoma was [9]. This study also provided insights on improving awareness amongst 
rural population by better ease and access to health care delivery systems and poor awareness was directly related to socioeconomic status and level of literacy [9]. In a study by Satyamangalam R.Ve women and those with a family history of glaucoma were more likely to be aware and had good knowledge of glaucoma [10].

Attitude was measured and $15(26.78 \%)$ patients experienced difficulty in using eye drops. Good self care practices of eye drop instillation was followed in $49(87.5 \%)$ patients

The impact of the disease on patients quality of life can be assessed with quality of life questionnaire .a study by Severn P. et al assessed the strengths and weaknesses of the several quality of life questionnaires. GQL-15 instrument established a graded response from no difficulty to severe difficulty in performing daily activities. The GQL-15 questionnaire is a disease specific questionnaire, easier to use, and had shown good internal consistency. It is a 15 item, 4 domain tool that is short and easy to use [15]. This questionnaire however neglects other aspects such as mental health, dependency or general health. In another study by Spaeth G, published literature on quality of life in patients with glaucoma was assessed. And they concluded that such an assessment is as important as the treatment offered by health care providers in the management of glaucoma [13]. The purpose of this survey highlights the importance of patient counseling and a significant improvement in the knowledge, attitude and practice of glaucoma in comparison to similar such studies that showed a low level of understanding of the disease process. A study by Rewri et al [16] did not find a relationship between age or gender and glaucoma awareness. Rewri et al also established a higher understanding of glaucoma amongst patients with higher level of education and in those with acquaintances with glaucoma patients. Similar trends were reported on other glaucoma awareness related studies [8].

Overall awareness on glaucoma in Indian population based studies is poor $[8,9,10]$. In yet another study by Kaur D et al concurred there is no gold standard quality of life assessment tool [17]. Severn $\mathrm{P}$ et al and Schacknow PN et al in their study on QOL assessment concluded that glaucoma specific and vision specific tools are better than generic tools to assess the impact of glaucoma on the quality of life of affected patients $[15,18]$.
This study highlights the importance of patient counseling having benefits in managing glaucoma. Limitations of our study include the small sample size, the possibility of an interviewer bias and lack of a comparative pre and post KAP questionnaire to show the effectiveness of counseling in this cohort of patients. Lester $\mathrm{M}$ et al established a significant $(\mathrm{P}<0.0001)$ correlation between the quality of life using the Viswanathan et all's questionnaire and MD ( $\mathrm{r}=0.79)$, $\operatorname{PSD}(r=-0.68)$ and $\operatorname{CPSD}(r=-0.61)[19]$.

With the increasing incidence of ocular surface disease with the use with anti glaucoma medication with BAK, Skalicky et al evaluated the relation between ocular surface disease and glaucoma quality of life and found an increased OSDI index in patients with increasing severity of glaucoma [20].

\section{Conclusion}

Our study highlights that awareness and dissemination of information on this asymptomatic disease can help patients adhere to management and follow up and in turn reduce the national and global burden of blindness due to glaucoma with simple measures such as improving knowledge, attitude and practice on instillation of eye drops in the right manner. There exist numerous quality of life questionnaires for glaucoma but each with its own limitations. A holistic approach beyond medical knowledge can help patients understand the nature of the disease and retard progression ensuring better quality of life for those afflicted with glaucoma.

Dr Elfride Farokh Sanjana: Previous affiliation: (when the study was done) Associate Professor, Department of Ophthalmology, Sri Ramachandra Medical College and Research Institute, Chennai -600116

Funding: Nil, Conflict of interest: None initiated, Permission from IRB: Yes

\section{References}

1. Resikoff S, Pascolni D, Etya'ale D, Kocur I, Parajasegaram R, Pokharel GP, et al. Global data on visual impairment in the year 2002.Bull World Health Organ 2004Nov;82(11):844-51.DOI:/S004296862004001100009 . 
2. George R,Ve RS, Vijaya L. Glaucoma in India: Estimated burden of disease. J Glaucoma.2010 Aug;19(6):391-7. DOI:10.1097/IJG.0b013e3181c4ac5b.

3. Quigley HA, Broman AT. The number of people with glaucoma worldwide in 2010 and 2020. Br J Ophthalmol.2006 Mar;90(3):262-

7.DOI:10.1136/bjo.2005.081224.

4. Tielsch JM, Sommer A, Katz J, Royall RM, Quigley HA, Javitt J. Racial variations in the prevalence of primary open angle glaucoma.The Baltimore eye survey.JAMA.1991Jul;266(3):369-74.

5. Vijaya L, George R, Baskaran M, Arvind H, Raju P, Ramesh SV, et al. Prevalence of primary open angle glaucoma in an urban South Indian population and comparison with a rural population. The Chennai Glaucoma Study.Ophthalmology.2010 Apr;58(3):24345.DOI:10.4103/0301-4738.62655.

6. Kwon YH, Kim CS, Zimmerman MB, Alward WL, Hayreh SS. Rate of visual field loss and long term visual outcome in primary open angle glaucoma .Am J Ophthalmol.2001Jul;132(1);47-56.

7. Oliver JE, Hattenhauer MG, Herman D, Hodge DO, Kennedy R, Fang -Yen M, et al. Blindness and glaucoma; A comparison of patients progressing to blindness from glaucoma with patients maintaining vision. Am J Ophthalmol.2002Jun;133(6):764-72.

8. Dandona R, Dandona L, John RK, McCarty CA, Rao GN. Awareness of eye diseases in an urban population in Southern India. Bull World Health Organ.2001;79(2):96-102.

9. Krishnaiah S, Kovai V, Srinivas M, Shamanna BR, Rao GN, Thomas R. Awareness of glaucoma in the rural population of Southern India. Indian $\mathbf{J}$ Ophthalmol.2005;53(3):205-8.DOI:10.4103/03014738.16685 .

10. Sathyamangalam RV, Paul PG, George R, Baskaran M, Hemamalini A, Madan RV,ET AL. Determinants of glaucoma awareness and knowledge in urban Chennai. Indian J Ophthalmol.2009;57(5):355-60.DOI: 10.4103/0301-4738.55073.

11. Nirmalan PK, Katz J, Robin A.L, Krishnadas R, Ramakrishnan R, Thulasiraj RD, Teilsch J. Utilization of eye care services in rural south India: the Aravind Comprehensive Eye Survey. $\mathrm{Br} \mathrm{J}$ Ophthalmol. 2004.Oct;88(10):1237-

41.DOI:10.1136/bjo2004.042606.

12. Dandona R, Dandona L, Naduvilath TJ, et al. Utilization of eye care services in an urban population in Southern India: the Andhra Pradesh eye disease study. $\quad \mathrm{Br} \quad \mathrm{J} \quad$ Ophthalmol 2000;84:2227.DOI:10.1136/bjo.84.1.22.

13. Spaeth G, Walt J, Keener J. Evaluation of Quality of life for patients with glaucoma. Am J Ophthalmol 2006. Jan;141(1):S3-14.

DOI: http;//dx.doi.org/10.1016/j.ajo.2005.07.075

14. Janz NK, Wren PA, Licther PR, Musch DC, Gillespie BW, Guire KE. Quality of life in newly diagnosed glaucoma patients: The Collaborative Initial Glaucoma Study. Ophthalmology 2001. May ;108(5):887-97.

15. Severn P, Fraser S, Finch T, May C. Which quality of life score is best for glaucoma patients and why ? BMC Ophthalmol.2008 Jan;34;4548.DOI:10.1186/1471-2415-8-2.

16. Rewri P, Kakkar M. Awareness, knowledge and practice : A survey of glaucoma in North Indian rural residents. Indian J Ophthalmol. 2014 .Apr; 62(4):48286.DOI:10.4103/0301-4738.132105.

17. Kaur D, Gupta A, Singh G.Perspectives on Quality of Life in Glauocma.J Curr Glaucoma Pract.2012JanApr;6(1):9-12. Doi:10.5005/jp-journals-10008-1101

18. Schacknow PN, Samples JR.Glaucoma in the Twenty-First Century.In:LimR., Goldberg I.,editors:The glaucoma book: A practical Evidenced-Based Approach to Patient Care. $1^{\text {st }}$ ed.New Youk:Springer;2010.pp 18-19.

19. Lester M, Zingirian M. Quality of life in patients with early, moderate and advanced glaucoma. Eye(Lond).2002 Jan;16(1):44-9. DOI:10.1038/sj.eye.6700036.

20. Skalicky SE,Glodberg I, McCluskey P. Ocular surface disease and quality of life in patients with glaucoma . Am J Ophthalmol 2012 Jan;153(1):1-9 DOI:10.1016/j.ajo.2011.05.033 


\section{How to cite this article?}

Elfride F.S., Philip S., Kishore S.R. Knowledge, attitude, practice and quality of life assessment in glaucoma- a cross sectional survey. Int J Med Res Rev 2016;4(12):2199-2204.doi:10.17511 /ijmrr. 2016.i12.20. 